\title{
LA PALABRA IMAGEN: ESTUDIO SEMIÓTICO-COGNITIVO DE LA POESÍA VISUAL DE FERNANDO MILLÁN, FELIPE BOSO Y CLARA JANÉS
}

\author{
THE IMAGE WORD: A COGNITIVE-SEMIOTIC STUDY OF THE VISUAL \\ POETRY OF FERNANDO MILLÁN, FELIPE BOSO AND CLARA JANÉS
}

\author{
Mario ALONSO GONZÁLEZ \\ Universidad Complutense \\ marioa12@ucm.es
}

\begin{abstract}
Resumen: El presente trabajo propone un estudio de la llamada poesía visual mediante un método integrado que hará confluir las herramientas de análisis de la teoría semiótica con las consideraciones de la Poética Cognitiva respecto a este tipo de objetos intermediales. De esta manera, de un estudio teórico inicial que permitirá extraer estas herramientas cognitivo-semióticas de análisis, se pasará a un estudio práctico, mediante el método previamente desarrollado, de obras concretas y variadas de poesía visual, seleccionadas entre la creación de Fernando Millán, Felipe Boso y Clara Janés.
\end{abstract}

Palabras clave: Poesía visual. Semiótica. Poética Cognitiva. Estudios intermediales.

Abstract: The present work develops a study on the so-called visual poetry by means of an integrated method which will fuse the analytical tools of the semiotic theory with considerations of Cognitive Poetics about this kind of intermedial objects. Therefore, from a theoretical study which will provide us with this cognitive-semiotic analytical tools, a practical study will follow with the analysis of specific and varied works of visual poetry, which will be selected within the works of Fernando Millán, Felipe Boso and Clara Janés.

Keywords: Visual poetry. Semiotics. Cognitive Poetics. Intermedial studies.

\section{INTRODUCCIÓN}

El objetivo del presente estudio es el de realizar un estudio semiótico-cognitivo de la poesía visual. Este trabajo partirá del desarrollo un método semiótico intermedial para el análisis de los elementos plásticos y textuales de la poesía visual. En segundo lugar, se recogerán las aportaciones de la teoría cognitiva a este análisis y caracterización de la poesía visual desde una perspectiva semiótica, que nos permitirán comprender mejor su función y recepción. En tercera instancia, realizaré también un estudio práctico, 
analizando desde las anteriores perspectivas las obras de tres autores: el poemario visual La palabra islas (1981) de Felipe Boso, dos criptogramas (Criptogramas, 1968-1973), un collage (Ariadna o la búsqueda, 1971-1973) de Fernando Millán y una composición poético-visual de Clara Janés en Espacios translúcidos (2006). De esta manera, se han elegido intencionadamente obras pertenecientes a la categoría de la poesía visual, pero que tienen notables diferencias entre sí, con la finalidad de intentar explorar algunas de las múltiples posibilidades que la poesía visual ha desarrollado.

El aspecto terminológico es complejo puesto que existen demasiadas denominaciones, movimientos y teorías muy variados dentro de lo que en este estudio se engloba como poesía visual. Lafuente (2014:17) habla de manera más general de "poesía experimental" como "un fenómeno plural y heterogéneo que, aun centrándose en las prácticas de la poesía, la desbordó para extenderse por otras artes". Por su parte, Elleström (2016) argumenta en contra del término de poesía visual que su especificidad no se basa en lo visual sino en lo icónico. De cualquier forma, será este término el que utilice, dada su carga convencional, para definir, las prácticas de poesía plurales y heterogéneas que tengan en común, como analiza Tsur (2000), una especial disposición grafémica que trascendería la dimensión puramente textual para ser transmedial.

La tradición de la poesía visual se remonta a la Antigüedad clásica, pasando por las importantes contribuciones de la poesía figurativa medieval; en España podríamos trazar su origen al siglo X con las composiciones del monje Vigilán (Romera Castillo, 1980). A pesar de mantenerse a lo largo de los siglos su carácter lúdico y ciertos componentes formales (Romera Castillo, 1980: 148-154), la poesía visual contemporánea nace en el siglo XX con nuevas formas y contenidos, resultantes del "desmantelamiento de los modos miméticos de reproducción de la realidad", sumado a una "atención unificada sobre la presencia del significante material" (Sarabia, 2007: 21). Su acta de nacimiento podría fijarse en torno a 1914 en Francia e Italia, con la publicación de los caligramas de Apollinaire y la poesía futurista de Marinetti, inspiradas en las nuevas perspectivas de las vanguardias plásticas, musicales y la emergencia del cine (Millán, 2005: 13), además de por la gran importancia y revalorización de lo visual en este siglo (Bohn, 1986: 2).

Estos movimientos van a desaparecer de los primeros planos de la creación y crítica literarias hacia 1928, para reaparecer tras la Segunda Guerra Mundial (Bohn, 1986: 6). Tiene lugar entonces un replanteamiento de la poesía de vanguardia, que va a centrarse en ideas más laterales de las primeras vanguardias, elaborando "teorías más o menos desarrolladas que de forma poco ortodoxa se proyectan en un movimiento" (Millán, 2005: 14). Dos de los movimientos principales son la poesía concreta y el letrismo. La poesía concreta tiene una gestación múltiple en Alemania (con Eugen Gomringer y Max Bense) y Brasil (con el grupo Noigandres) y va a proponer, en palabras de Bense, utilizar el lenguaje "no sólo como portador de significados, sino por encima de esto, y tal vez de un modo más acentuado como acto fonético y visual" (Millán, 2005: 26). Por su parte, el letrismo se va a centrar en la materialidad del signo lingüístico: en palabras de su 
fundador, Isidore Isou, "es el arte que acepta la materia de las letras reducidas y convertidas simplemente en ellas mismas" (Millán, 2005: 21).

En España, la influencia del concretismo y el letrismo va a originar la aparición del experimentalismo visual en 1948 con el grupo Dau al set, donde destacan Cirlot y Brossa, quienes además continuarán su actividad experimental una vez el grupo se disuelva. Posteriormente también el grupo Problemática-63, formado, entre otros, por Fernando Millán, tendrá gran relevancia, separándose después en los grupos N.O. y C.P.A.A. (Lafuente, 2014: 48-54). Sin embargo, la poesía visual va a ocupar tan solo un espacio marginal en la cultura literaria española, tanto desde la perspectiva del mercado literario, como desde la perspectiva académica. Aún hoy en día estas tendencias cuentan con una visibilidad reducida y su importancia, tanto dentro de la producción poética española como europea, necesita todavía ser reivindicada.

\section{MÉTODO SEMIÓTICO DE ANÁLISIS}

Siguiendo a Bohn (1986: 5), la poesía visual se consideraría un "sistema semiológico de segundo orden" que tendría la siguiente estructura esquemática:

\begin{tabular}{|c|c|c|}
\hline 1. Significante & 2. Significado \\
\hline \multicolumn{2}{|c|}{ 3. Signo } \\
I. Significante & II. Significado \\
\hline \multicolumn{2}{|c|}{ III. Signo } \\
\hline
\end{tabular}

Tabla 1. Estructura del signo semiótico (III) del poema visual, que, de abajo a arriba, se dividiría en significante (I) y significado (II). A su vez, el significante (I) actuaría como signo plástico (3), que se dividiría de nuevo en significado (2) y significante (1).

Traducción del esquema de Bohn (1986: 6).

De esta manera, la atención de las vanguardias sobre la materialidad del signo lingüístico, que se había considerado como mero vehículo textual, lleva a tratarlo, a su vez, como signo. Este nuevo signo (el grafo) se propone como plástico y sonoro, si bien la perspectiva plástica va a predominar y el aspecto sonoro se apreciará sólo marginalmente. En la terminología de Peter Wagner (Icons - Texts - Iconotexts, 1996), el poema visual podría considerarse un iconotexto, según la definición que da Pimentel:

No sólo la representación visual es leída/escrita [...] como texto sino que al entrar en relaciones significantes con el verbal le añade a este último formas de significación [...] del orden de lo icónico y de lo plástico, construyendo un texto complejo en el que no se puede separar lo verbal de lo visual (Pimentel, 2003: 206-207).

Elleström (2016: 439-440) reincide en esta perspectiva, afirmando que la especificidad de la poesía visual es su carácter icónico, mientras que toda poesía es visual, en tanto que es leída y hay elementos (el verso y el espacio en blanco) que así la definen. La iconicidad sería "[la] creación de significado basada en la semejanza, ya sean los 
significantes y significados visuales, auditivos o cognitivos" y tendría una gradación (Elleström, 2016: 440-441). Sin embargo, el propio Elleström (2016: 440) admite que la perspectiva icónica no agota las características de la poesía visual. Habría que recurrir, por lo tanto, a la noción de transmedialidad, perteneciendo la poesía visual a una de las "formas de expresión y representación híbridas" de las que habla De Toro (2007: 26) en su definición: "El concepto de transmedialidad [...] no significa el intercambio de dos formas mediales distintas, sino una multiplicidad de posibilidades mediales. Además, este concepto incluye formas de expresión y representaciones híbridas". Precisamente debido a este carácter transmedial, Sarabia (2007: 23) enfatiza la necesidad de una interdisciplinariedad en el estudio de la poesía visual.

Según Bohn (1986: 69), existen tres tipos de relaciones transmediales entre los diferentes elementos de un poema visual: textual-textual, visual-visual y textual-visual; es decir, entre los diferentes elementos textuales, entre los diferentes elementos visuales (donde, naturalmente, se incluyen las grafías en tanto que visuales) y entre los elementos textuales (en su conjunto) y los elementos visuales (en su conjunto). Estos tres tipos de relaciones pueden ser metafóricas o metonímicas, siguiendo la teoría jakobsoniana, dependiendo de si se basan en asociaciones por analogía o por contigüidad (Bohn, 1986: 69-79). Además, en el caso de conjuntos coherentes de poemas visuales se pueden estudiar las "dinámicas de grupo" a través de un "análisis macroestructural” (Bohn, 1986: 80-81). En estos conjuntos las interacciones se multiplican, dado que los tres tipos relacionales anteriores se dan dentro de cada poema y en todas las combinaciones posibles con los elementos textuales o visuales del resto de poemas. El resultado de esta multiplicación, como demuestra Bohn, es que la mayoría de las relaciones posibles resultantes son de carácter textual-visual. Además, Bohn define tres tipos de relaciones en las dinámicas de grupo: primarias (los tres tipos de relaciones dentro de un mismo poema), secundarias (relaciones de elementos del mismo tipo en diferentes poemas) y terciarias (relaciones de elementos de distinto tipo en diferentes poemas).

Por lo que respecta a la recepción, se ha demostrado la falsedad de la hipótesis de la simultaneidad visual y textual en el proceso de significación, dado que, naturalmente, lo textual carece de la posibilidad de una lectura instantánea. Como afirma Bohn (1986: 66), "en la práctica, esto significa que la mente procede cumulativamente, manteniendo elementos en suspensión mientras los ordena y reordena en una búsqueda continua de significado". Además, este proceso acumulativo se llevaría a cabo a través de movimientos hacia adelante y hacia atrás, falsando y verificando hipótesis y expectativas, en procesos de anticipación y retrospección que recorren los tres tipos de relación comentados (textual-textual, visual-visual y textual-visual). Por lo tanto, la única simultaneidad posible ocurre a posteriori, cuando se observa el poema al final de este proceso acumulativo: "solo al final del poema pueden fusionarse los diferentes elementos semánticos para formar una gestalt conceptual” (Bohn, 1986: 66).

Como se ha visto, el proceso de significación requiere de una colaboración extremadamente activa, incluso creativa, del lector, debido a la compleja recepción de 
este tipo de poesía y su inherente ambigüedad, de forma que cada lector traza "su propio trayecto de lectura" (Velázquez, 1987: 43). De esta manera, en palabras de Bohn (1986: 8), la poesía visual "disuelve las barreras tradicionales entre el lector y el texto, [...] agudiza la sensibilidad del lector y motiva la participación en la creación del poema". En general, esta nueva forma de lectura conlleva una "nueva forma de enfocar nuestro mundo como algo que puede ser leído" (Millán, 2005: 20).

Por último, queda volver a la marginación que ha sufrido el aspecto sonoro del significante lingüístico tanto desde la creación como desde la crítica de la poesía visual. Este aspecto es considerado por Max Bense cuando afirma que en la poesía visual "la palabra aparece simultáneamente como medio poético de configuración en el plano del morfema (en el significado), en el plano del grafo (en la perceptibilidad figural) y en el plano del fonema (en el discurrir sonoro)" (Millán, 2005: 26). Sin embargo, esta última consideración no se ha explotado en la mayor parte de la poesía visual (a excepción, quizás, de algunos movimientos de vanguardia iniciales como el futurismo y el dadaísmo), que se ha centrado en la relación entre los elementos textuales y visuales; incluso el propio término de poesía visual es significativo de esta desigualdad.

\section{TEORÍA COGNITIVA DE LA POESÍA VISUAL}

La teoría cognitiva de la literatura constituye una disciplina de reciente incorporación a los estudios literarios, entre los cuales aún está configurando su campo de investigación. De esta manera, podemos encontrar ya algunos, aunque escasos, desarrollos teóricos que estudian los procesos cognitivos involucrados en la recepción de la poesía visual. Entre ellos, destaca Reuven Tsur, quien ha elaborado, además de su importante teoría cognitiva de la poesía lírica, iluminadoras reflexiones acerca de la cognición de la poesía visual en su artículo "Picture Poetry, Mannerism, and Sign Relationships", publicado en Poetics Today en el año 2000. Además, es notable también la aportación más reciente de Mike Borkent (2014 y 2015), quien ha basado su tesis doctoral, precisamente, en un estudio semiótico-cognitivo de la poesía visual.

El artículo de Tsur parte de la evidencia de que, aunque la poesía requiere de una disposición especial o patrón (patterning) de los signos (Tsur, 2000: 764), ya sea en el orden fonológico, morfosintáctico, semántico o, incluso, grafémico, parecería que existe, sin embargo, una diferencia en cuanto a la percepción de la naturalidad de esta disposición. De manera que la especial disposición grafémica de la poesía visual nos parecería artificial, frente a la especial disposición en el resto de niveles en la poesía no visual, que nos parecería natural. Esta diferencia no podría asociarse simplemente a la tradición, que habría naturalizado ciertas características, ya que, como hace notar el propio Tsur (2000: 77), ciertos tipos de disposición grafémica significante han existido siempre. Por otra parte, incluso aunque se tratara simplemente de una convención literaria, Tsur (2010) demuestra también cómo las convenciones literarias son originadas por razones cognitivas que se fosilizan. 
En cambio, para explicar esta situación Tsur (2000: 759) afirma, en primer lugar, la existencia de una "diferencia cualitativa entre los artefactos poéticos que consisten en patrones de significantes y aquellos que consisten en patrones de significados". En segundo lugar, Tsur (2000: 765) explica por qué la disposición de elementos morfosintácticos y fonológicos también es percibida como más natural que la de elementos grafémicos. Se ha demostrado experimentalmente que, cuando se presentan elementos yuxtapuestos con características distintivas, estas diferencias son percibidas de forma más aguda cuando la forma de presentación es visual que cuando es verbal. De esta forma, por ejemplo, ante una disposición grafémica (visual) resultará más evidente y "artificial”, mientras que las disposiciones funcionarán como una "fusión armónica en el fondo de nuestra mente" (Tsur, 2000: 763). Por añadidura, Tsur (2000: 769) señala que existe otra diferencia que contribuye a esta diferente percepción de naturalidad: mientras que el procesamiento fonético del lenguaje es innato, el procesamiento grafémico es "un artificio hecho por el hombre".

Además, se ha demostrado que el procesamiento del lenguaje se realiza mediante una "percepción categorial" (Tsur, 2000: 769), en sus diferentes niveles. La última diferencia que señala Tsur entre la disposición grafémica y fonológica estriba en este aspecto: mientras que la segunda favorece dicho procesamiento categorial del lenguaje, la primera lo dificulta, poniendo en evidencia la materialidad del signo, desautomatizando la percepción categórica (Tsur, 2000: 775).

Además, el artículo de Tsur contiene otras reflexiones reveladoras acerca de la naturaleza de la poesía visual, su funcionamiento, recepción y valoración. Estrechamente relacionado con lo expuesto anteriormente, Tsur (2000: 768) afirma que las disposiciones de los signos que resultan más "suaves", más fáciles y naturales, generan una respuesta emocional; mientras que aquellas que, por el contrario, resultan discordantes generan una respuesta witty, es decir, del ingenio. Esto explicaría por qué resulta difícil tener una respuesta emocional ante la poesía visual que, como ya hemos visto, se corresponde a la segunda categoría; en cambio, la respuesta natural suele ser intelectiva.

Por otro lado, Tsur (2000: 751, 757) afirma que el placer estético producido por la poesía visual tendría su causa en que de esta manera los lectores reafirmarían que "sus recursos adaptativos funcionan adecuadamente cuando son alterados". Es decir, que, cuando la disposición grafémica desautomatiza su percepción categórica (que sería un proceso de economía cognitiva), sus "recursos adaptativos" podrían reorganizar la percepción satisfactoriamente en torno a nuevos principios.

Finalmente, Tsur también aporta un aspecto del estudio de la poesía visual que no había aparecido antes en esta discusión y que tiende a evitarse en la crítica: el aspecto axiológico. Según Tsur (2000: 775), la adecuación de un poema visual ocurrirá cuando se ajusten de forma adecuada lo textual y lo visual, dado que sólo la integración de ambos elementos puede originar el "shock emocional". Sin embargo, el poema no debe componerse tampoco de relaciones textuales-visuales demasiado complejas, porque en este caso el lector no sería capaz de integrarlas y sólo podría contemplarlas separadamente 
(Tsur, 2000: 776). Por lo tanto, es ideal un balance entre complejidad y simplicidad. Además, Tsur señala también la importancia en el efecto producido del valor poético inherente del texto.

Por otra parte, Mike Borkent aporta al estudio de la poesía visual una actualización respecto a las concepciones de Tsur, a través de las nuevas nociones de los más estudios cognitivos "de segunda generación" (Borkent, 2015: 28-33; Gibbs, 2006). En esta segunda generación se ha enfatizado en el embodiment (corporalidad incorporada) de los procesos cognitivos, agrupados en sistemas dinámicos de cognición multimodal:

Una perspectiva de la percepción y de la cognición que enfatiza su corporeidad: a través de qué interacciones corporales con entornos específicos (experiencias sensomotoras) se construye la conceptualización de maneras que difuminan los límites entre sujeto y objeto (Borkent, 2014: 10).

De esta manera, todo proceso cognitivo (incluido el lenguaje) resulta de una interacción dinámica entre la mente humana, el cuerpo y el entorno, en lo que se denomina "cognitive ecology" o "embodiment" (Borkent, 2015: 28). Esto, naturalmente, rebate completamente la concepción tradicional de una cognición y percepción puras, como procesos mentales (o incluso espirituales) aisladas del cuerpo; así como la concepción del lenguaje como estructurador de la cognición y la percepción, mientras que se revela como producto de una experiencia corporizada (embodied experience) (Borkent, 2015: 29-30). Desde esta perspectiva, Borkent propone una variación cognitiva del concepto tradicional de improvisación para explicar la manera en que se escribe y se lee poesía visual. Define la improvisación como "una particular práctica creativa o actitud artística hacia un medio y sus convenciones", que funcionaría por confluencia de "respuestas cualificadas y, al mismo tiempo, automáticas (inconscientes) y dinámicas, ante cualquier medio y sus modos de representación" (Borkent, 2014: 11).

Como se ha dicho, sería mediante este proceso de improvisación como funcionaría tanto la escritura como la lectura de la poesía visual: "Las mismas habilidades cognitivas que alimentan la improvisación textual en la creación de poesía postlingüística también respaldan los procesos dinámicos interpretativos de los espectadores de estos poemas" (Borkent, 2014: 14). Además, el proceso de improvisación estaría basado en la idea de la simulación mental (actualización y generalización del concepto de mental performance en Tsur, 1992: 30): "este proceso de reanimación facilita conexiones e inferencias innovadoras y/o ficticias entre cosas y experiencias, desde la comprensión básica de la percepción hasta elaboradas abstracciones metafóricas del lenguaje y de otros modos de expresión" (Borkent, 2014: 14).

En particular, en la lectura e interpretación de las artes plásticas y visuales tendría lugar un proceso mental de movimiento ficticio (fictive motion): "el movimiento ficticio ocurre cuando los lectores o espectadores conceptualizan objetos estáticos como móviles, como por ejemplo entender que una línea de puntos estáticos recorre una página" (Borkent, 2014: 15). Este proceso sería también aplicable, según Borkent, a la poesía 
visual, de manera que en su lectura e interpretación se procedería a establecer conexiones dinámicas que le otorgarían un cierto movimiento o direccionalidad al conjunto de signos estáticos impresos en el papel. Será de esta manera como se elaborarán los análisis prácticos siguientes.

Por último, antes de pasar a estos, cabe señalar que Borkent, de una manera similar a Tsur, asocia el placer producido por la poesía visual a la complejidad y cuestionamiento de nuestros modos de percepción y de concepción, lo cual "aumenta significativamente el trabajo (y el placer) cognitivo de los lectores mientras intentan interpretar los poemas" (Borkent, 2014: 8).

\section{ESTUDIO PRÁCTICO DE LA POESÍA VISUAL ESPAÑOLA}

Una vez descritas las características semiótico-cognitivas de la poesía visual y definido el método semiótico, así como las aportaciones cognitivas que se pueden realizar al mismo para profundizar en el estudio práctico de la poesía visual, pasaré precisamente a dicho análisis, cuyo corpus será el siguiente: el poemario visual La palabra islas (1981) de Felipe Boso, dos criptogramas (Criptogramas, 1968-1973) y un collage (Ariadna o la búsqueda, 1971-1973) de Fernando Millán y una composición poético-visual de Clara Janés en Espacios translúcidos (2006). Estas obras, como ya he advertido, tienen notables diferencias entre sí, lo cual permitirá, por un lado, explorar algunas de las múltiples posibilidades que la poesía visual ha desarrollado y, por otro lado, al aplicar un método semiótico-cognitivo común al análisis de todas las obras, probar la consistencia y la capacidad hermenéutica de dicho método.

\subsection{Felipe Boso: una metáfora del aislamiento del signo}

La palabra islas (1981) es uno de los pocos libros que el exiliado Felipe Boso (19241983) ve publicados en vida y se inscribe dentro de las tendencias de la poesía concreta. Como excepción, realizaré un análisis del libro en su conjunto, dado que se caracteriza por una coherencia y una cohesión de la que resulta mucho más interesante y reveladora un estudio de conjunto, analizando la forma teorizada por Bohn (véase la sección 2) de las dinámicas de grupo. El total de la obra presenta varios subconjuntos diferenciados, de manera que analizaré cada uno de ellos por separado, para después derivar conclusiones de la interacción entre ellos en el conjunto total de la obra. El primero y más obvio de estos subconjuntos sería el que conforman mayormente las páginas impares (con alguna excepción), constituidas por un listado vertical en orden alfabético de los nombres en minúscula de islas de todo el mundo, organizadas en grupos arbitrarios de diferente número (véase un ejemplo en la Figura 1 en el Anexo).

Por otro lado, las páginas pares (salvando de nuevo las excepciones) se dividirían en dos subconjuntos. De esta manera, en segundo lugar, tendríamos un subconjunto formado por páginas donde nombres aleatorios de islas tienden a representar figurativamente 
diferentes formaciones de islas, incluyendo en este caso tipografías y tamaños de letra variables, así como repeticiones de letras (en vertical u horizontal) de un cierto nombre de isla para lograr así la forma insular (véase un ejemplo en Figura 2 del Anexo). En tercer lugar, el último de los subconjuntos estaría constituido por páginas donde los grafemas de la palabra palabra $(\mathrm{p}-\mathrm{a}-\mathrm{l}-\mathrm{b}-\mathrm{r})$ formarían visualmente diferentes figuras geométricas (véase un ejemplo en Figura 3 del Anexo).

Si se considera el primer subconjunto, se observa que, en el nivel de relación textualtextual, estaría fuertemente cohesionado mediante la característica léxica compartida (todas las palabras son nombres de islas), que en su repetición vertical incesante daría lugar a un fortísimo paralelismo estructural, que crearía a su vez un elevado ritmo semántico; además, la repetición de la primera letra crearía una aliteración inevitable, mientras que también destacaría la estricta ordenación en orden alfabético, principio bajo el cual avanza el poema. En el nivel visual-visual se observa que los nombres de las islas se encuentran organizados (a través del fictive movement de Borkent) en grupos de número variable $\mathrm{y}$, de esta forma, aislados los unos de los otros por el silencioso espacio en blanco de la página, que ejerce un papel significativo.

Por otro lado, la repetición alineada de cada letra del abecedario y de las palabras con la misma tipografía dan lugar a una homogeneidad. En la interacción de ambos niveles (relación textual-visual), se produce una asociación de la carga léxica textual con la forma de organización visual de los nombres, de manera que se encuentra que los grupos de nombres de islas formarían, a su vez, islas visuales, en una relación claramente metafórica. Estas islas de islas, como ya he dicho, se hallarían aisladas (sirva la redundancia para reincidir en la sensación de soledad e incomunicación) las unas de las otras por el espacio blanco de la página. Además, la repetición homogénea e incansable en el nivel visual (y textual), sumada al elevado ritmo textual, daría lugar a una sensación apabullante de infinitud, como si las islas nunca acabaran, como si todo fuera isla. Naturalmente, también existe un juego paratextual claro con el título, La palabra islas, constituyendo este subconjunto una serie de islas de palabras (nombres) de isla.

Pasando a analizar el segundo subconjunto, se observa una situación análoga a ciertos aspectos del primer subconjunto. De nuevo, la relación textual-textual se establecería entre nombres de islas que, asociados a su conformación visual, conformarían una vez más islas gráficas de islas de palabras, recuperando el mismo juego paratextual. Sin embargo, en este caso las islas gráficas se corresponderían de manera más exacta a posibles formas de islas y archipiélagos, posicionando para ello las palabras en toda la superficie de la página (y no verticalmente en estricto orden). En esta acción, se cumple una aspiración, según Muriel Durán (2000: 210), de la poesía concreta: “que las palabras, liberadas de la esclavitud de la frase, expusieran su dinamismo interno y crearan formas autónomas, en las que predominara la vertiente visual".

Además, se utilizan también para ello tipologías y tamaños de letra variables, así como repeticiones de letras sueltas de las palabras, lo que genera un énfasis sobre la materialidad de la palabra, que ya no está dispuesta de manera homogénea ni ordenada, 
sino que en su variabilidad genera diferentes texturas que conforman las diferentes formas de islas. Por otro lado, la sensación de infinitud se habría perdido, ya que no hay ninguna larga lista, sino que cada poema (cada página) conforma una única isla o, en todo caso, un archipiélago, separada de las/los demás, de nuevo, mediante el silencioso espacio en blanco de la página. De esta forma, se encontraría de nuevo una sensación de soledad e incomunicación, donde las diferentes islas o archipiélagos ni siquiera disponen de una contigüidad, dada la alternancia de subconjuntos, disminuyendo la fuerza de su interrelación (relación secundaria y terciaria, según la terminología de Bohn), que se limitaría a un paralelismo intercalado.

Por lo que respecta al tercer subconjunto, en este caso no se encuentra una relación figurativa como en los anteriores. El nivel textual-textual es casi inexistente, dado que sólo se encuentran los grafemas de la palabra palabra en desorden cacofónico. Por lo tanto, predomina el aspecto visual, consiguiendo así los grafemas de la palabra palabra (significativamente) una libertad total, aún mayor del caso anterior: el significante palabra, en primer lugar, se vería escindido es sus subpartículas, y se vería liberado cualquier relación con el plano de su significado. Los grafemas aparecerían sólo en tanto que grafemas, formas plásticas puras que conformarían (en una relación metonímica), a su vez, formas puras de la geometría: triángulo, rombo, cuadrado, rectángulo, flecha, etc. De esta manera, el grafema, desordenado textualmente, se organizaría en formas visuales muy concretas, adquiriendo así un sentido en el nivel visual del que carecen en el nivel textual. Como en el caso anterior, no se hallaría ninguna sensación de infinitud, sino de aislamiento ya que, rodeadas del silencioso espacio blanco de la página, estas formas puras de la geometría conformarían, a su vez, islas geográficas. Por último, de nuevo las interrelaciones entre estas islas geométrico-geográficas se limitarían a un paralelismo intercalado.

Finalmente, a nivel de macroestructura se pueden observar diversos aspectos comunes y tendencias. En primer lugar, como se ha visto, todos los subconjuntos se caracterizan por la agrupación visual en forma de islas, en diferentes formas y grados figurativos. En segundo lugar, existe una tendencia de libertad creciente de la palabra y, más allá, del grafema (en el orden comentado de los subconjuntos): se pasa de la estricta ordenación alfabética y el respeto de las líneas horizontales tradicionales (subconjunto 1) al espacio abierto donde la palabra se mueve con libertad e incluso se desgajan de ella ciertos grafemas (suconjunto 2), para llegar finalmente a una escisión completa del grafema de la unidad originaria de la palabra y su significado (subconjunto 3), pasando el grafema a constituir únicamente un signo plástico, concretamente el más puro, asociado a las formas geométricas más puras.

De esta manera, se extraerían dos significaciones macroestructurales. Por un lado, la isla-palabra se escinde en islas(/archipiélagos)-grafemas, que ya han sido aisladas de todo significado lingüístico-textual, llegando a perder también, en su búsqueda de libertad y de pureza, su significado figurativo (su forma de islas, pasando a ser las formas puras de la geometría). Esta búsqueda, que empieza siendo geográfica (metaforizada en la isla), en 
la libertad del espacio en blanco de la página, terminaría siendo geométrica (metaforizada en las figuras). Además, la sensación de aislamiento, soledad e incomunicación resaltada en cada subconjunto contribuyen semánticamente a esta macroestructura. De esta manera, al final el grafema y, por metonimia, la palabra, habrían perdido toda significación y conformarían tan sólo formas puras, islas rodeadas del mar blanco y silencioso de la página, desde las que resultaría imposible comunicar.

\subsection{Fernando Millán: la conceptualización de la percepción}

Fernando Millán (Jaén, 1944) es uno de los nombres clave en la creación y difusión del arte experimental español en la segunda mitad del siglo XX, habiendo trabajado en "poesía textual, sonora, visual, plástica, poemas, libros-objeto y acciones poéticas" (Lafuente, 2014: 195). Como ya he comentado, fue fundador, junto con Julio Campal, del grupo Problemática-63 y después se mantendría en una de sus escisiones, el grupo N.O., a la muerte de Julio Campal. En el presente estudio, analizaré dos tipos de sus poemas visuales: en primer lugar, dos de sus Criptogramas (1968-1973); y en segundo lugar uno de los collages de su libro de poesía visual Ariadna o la búsqueda (1971-1973).

\subsubsection{Criptogramas}

Como describe Lafuente (2014: 64), los criptogramas de Millán están constituidos por una palabra "cuya escritura se somete a la distorsión de una especie de rejilla que procede del mundo plástico del arte cinético y que reclama un esfuerzo más retiniano que intelectivo". Esta técnica puede observarse, en los criptogramas estudiados, Sueño y Mentira (véase Figuras 8 y 9 en Anexo): las palabras SUEÑO y MENTIRA en mayúscula aparecen distorsionadas por rejillas en diferentes sentidos (horizontal, vertical y diagonal) y con diferentes formas (triángulos y círculos), recordando estas rejillas, en blanco y negro, al mundo cinematográfico. No obstante, se debe notar que tanto la forma de las rejillas como la intensidad de la distorsión (ocultando más o menos la palabra) son diferentes en los dos criptogramas (precisamente por este motivo se han seleccionado dos criptogramas para el análisis), lo cual tendrá connotaciones significativas asociadas a la propia palabra.

De manera general, se puede observar que, de nuevo, la materialidad del signo es colocada en primer plano. Las rejillas, como ya he comentado, causan una distorsión óptica en el significante textual, de tal forma que la percepción de la palabra se ve afectada por la percepción óptica distorsionada, de manera que los componentes textual y visual quedan inextricablemente unidos. De esta manera, se evidencia que en la percepción del significante tradicional existe un componente plástico y óptico dado que el propio significante es gráfico, aspecto que se había ignorado históricamente. Sin embargo, esto no implica, como afirmaba Lafuente, que la lectura reclame "un esfuerzo más retiniano 
que intelectivo", dado que, como hemos visto con Tsur y Borkent, ambos están estrechamente unidos: la percepción conlleva un procesamiento conceptual.

Por otro lado, ha de notarse que la forma visual elegida de la distorsión guarda una clara analogía con el significado de las palabras a cuyo significante se aplica esta distorsión. Tanto la palabra sueño como la palabra mentira conllevan en su significado una distorsión de la realidad, si bien en diferentes sentidos, como analizaré a continuación. De esta forma, esta distorsión de la realidad del significado se asociaría con la distorsión visual a través de una relación metafórica. Esta distorsión, a su vez, entraría también en relación con la atención puesta sobre la materialidad de la palabra, que comentaba anteriormente, dado que esta focalización en el significante y su uso intelectivo busca demostrar también una distorsión: la palabra se ha usado de manera parcial, sin explorar su completa capacidad semiótica.

Sin embargo, como ya he mencionado, se encuentran diferencias visuales y de significado textual entre ambos criptogramas. En primer lugar, existe una diferencia en cuanto a la legibilidad (desde la perspectiva textual) o intensidad distorsiva (desde la perspectiva visual): el criptograma Mentira presenta una mayor distorsión que el criptograma Sueño, de forma que en el primero difícilmente podríamos leer MENTIRA a no ser por la referencia paratextual del título incluido por el autor en la esquina inferior derecha. Ya he comentado que ambas distorsiones tenían una relación metafórica con el significado léxico de las palabras distorsionadas; también esta diferencia guarda una analogía con la diferencia léxica entre ellas. En el sueño la distorsión de la realidad es más clara, es decir, al menos en la tradición cultural occidental contemporánea, no suelen entrecruzarse los ámbitos del sueño y la realidad, siendo considerado el primero como una recreación imaginativa. En cambio, en la mentira la distorsión de la realidad no es tan clara, en el sentido de que muchas veces resulta imposible de identificar o de separar de la realidad (donde, sin duda, entraríamos en el problema epistemológico de "¿qué es verdad?"). De esta forma, la mayor distorsión de Mentira encuentra una correspondencia léxica.

En segundo lugar, mientras que en Mentira las rejillas tienen contornos de líneas rectas que forman triángulos, en Sueño se introducen rejillas con forma circular. Esto podría tener también una relación de analogía léxica con la palabra sueño. A través de la introducción de las formas circulares, no sólo se dificultaría la legibilidad, sino que se distorsionarían y suavizarían los bordes de los grafemas, introduciendo de esta manera un aspecto onírico, puesto que en los sueños también se distorsionan y suavizan las formas claras de la realidad.

\subsubsection{Ariadna o la búsqueda}

En su obra Ariadna o la búsqueda, Millán construye cuarenta fotocollages compuestos por letras, signos, fotografías y figuras geométricas. Como recoge Lafuente, cada uno de estos elementos tiende a realizar funciones diferentes: 
Las letras, que representan la escritura, mantienen cierto orden lineal y geométrico, pero no configuran palabras con sentido lingüístico, por lo tanto carecen de narratividad y sentido enunciativo. Los signos son todos del mismo tipo, son flechas de señalar dirección. Las imágenes fotográficas presentan un cierto orden, pero tampoco generan un discurso, al igual que las letras no poseen continuidad narrativa, pero sí son enunciativas (Lafuente, 2014: 64).

De este conjunto he seleccionado para el análisis uno solo de los fotocollages (véase Figura 10 en el Anexo), al cual se le suponen características paradigmáticas para representar, al menos en cierta medida, al resto. En éste, se puede observar que el fondo es una fotografía en blanco y negro de un ambiente rural, con hierba, árboles y ovejas. Sin embargo, sólo podemos ver este fondo a través de tres tipos de figuras, que actúan como ventanas a él, puesto que el resto está en negro. Estos dos tipos de figuras son, por un lado, letras, que aparecen deformadas, en diferentes tamaños y en una anómala tipografía que engruesa sus líneas para permitir ver la fotografía de fondo a través de ellas; por otro lado, flechas gruesas (también para ver a través de ellas) que se encuentran en las esquinas y señalan hacia el centro, orientando así nuestra mirada; y, por último, algunas otras formas no fácilmente asimilables como letras.

En primer lugar, cabe resaltar que no existe nivel textual como tal, ya que la palabra se ha escindido en sus diferentes grafemas, que, como hemos visto con Boso, se han liberado de su significado textual para pasar a tener una función plástica: en este caso, como ventanas a la significación plástica de la fotografía de fondo. Esta utilización de los grafemas como ventanas podría constituir un guiño a la concepción tradicional de la palabra como ventana transparente al mundo y a las ideas, que, naturalmente, sería rebatida de esta manera ${ }^{1}$; de manera irónica, ya que en este caso pasaría a ser una ventana transparente al mundo (recogido en la fotografía), pero no lingüística, sino plástica. En segundo lugar, las flechas dirigen la atención hacia el centro: hacia las letras como ventanas abiertas a la fotografía de fondo.

En tercer lugar, precisamente, se encuentra la fotografía del locus amoenus de fondo. Para la explicación de la introducción de la fotografía en el collage, partiré de Louvel (2016: 148), quien destaca la relación obvia y estrecha entre la fotografía y la memoria, de manera que la fotografía suele tener una función relacionada con el pasado y con el recuerdo. De esta manera, la significación de esta fotografía estaría ligada a un recuerdo de ese lugar rural, pastoril, de una visión de una naturaleza idealizada e intacta. Relacionando esta significación con lo anteriormente discutido, encontraríamos que la palabra (o, más exactamente, el grafema) funciona como ventana abierta al recuerdo. De nuevo, esta idea de la palabra como ventana al recuerdo tiene una larga tradición; sin embargo, también en este caso la ventana no va a ser lingüística sino plástica, donde se halla una ruptura significativa, reincidiendo, una vez más, en el componente gráfico de

\footnotetext{
${ }^{1}$ Precisamente, Borkent (2015: 35) afirma que la poesía visual, de manera general, rompe definitivamente con esta "conduit fallacy".
} 
las palabras. Además, el recuerdo es de una naturaleza idílica, quizás sugiriendo que a través de una nueva concepción plástica de la palabra se puede recuperar una visión más pura del mundo, de la naturaleza, volver a esa edad dorada de los orígenes.

Por último, las flechas, como ya he dicho, centrarían nuestra mirada en los grafemas como ventanas a la fotografía, al recuerdo; por lo tanto, su función es la de enfatizar las significaciones anteriores.

\subsection{Clara Janés: el símbolo transmedial}

Clara Janés (Barcelona, 1940) es miembro de la RAE, traductora y laureada poeta. Si bien la mayor parte de su poesía es, digamos, textual, se ha atrevido en más de una ocasión también con la poesía visual. En el presente estudio, analizaré su poema Anhelo vertical (véase Figura 11 del Anexo) que se incluye en el libro Espacios translúcidos (2006). Esta composición consta de tres elementos principales, que analizaré en primer lugar por separado: el texto del poema en prosa titulado "Anhelo vertical", el poema visual que también tiene por título "Anhelo vertical" y la cita de Cioran. Por lo tanto, este conjunto formaría claramente un iconotexto según la definición dada por Pimentel (sección 2), dado que se nos obliga a leer la imagen como texto, al tiempo que el texto adquiere una significación icónica de la imagen. De esta manera, imagen (poema visual, más exactamente) y texto quedarían estrechamente unidos mediante relaciones de transmedialidad, que analizaré también a continuación.

Empezaré en primer lugar por el poema visual, dado que este tipo es el objeto de este estudio y su análisis ayudará a orientar y delimitar los posibles significados del hermético $\mathrm{y}$ ambiguo poema en prosa (y viceversa). Este poema visual, de una gran belleza y capacidad sugestiva, tiene una composición bastante sencilla o, si se quiere, de pocos elementos, aunque muy significativos simbólicamente. De esta forma, se observa una granada (fotografiada ${ }^{2}$ y recortada) que cuelga de la parte superior de la página a través de un tallo negro pintado, y de la cual caen letras $O$ (una vez más, como grafemas con significación plástica y sin significación textual) como si fueran sus granos. Para desentrañar la significación de esta composición, partiré de la simbología de la granada según los diccionarios de símbolos de J. Chevalier (1991) y J. E. Cirlot (2004). Según éstos, existen varias posibilidades simbólicas para la granada que nos interesan:

a) Fecundidad reproductiva (Chevalier, 1991: 538).

b) Fecundidad divina, mística (Chevalier, 1991: 538).

c) Relacionada con Perséfone y la culpa/tentación: "Perséfone, por haberlo comido, pasará un tercio del año 'en la obscuridad brumosa y los otros dos al lado de los Inmortales"” (Chevalier, 1991: 538).

d) "Ajuste entre lo múltiple y diverso en el seno de la unidad" (Cirlot, 2004: 236)

\footnotetext{
2 En el prólogo del libro se especifica que las fotografías han sido "llevadas a cabo por la propia Clara" (Janés, 2006: 59).
} 
e) "Los griegos creerían que las granadas habían brotado de la sangre de Dioniso" (Cirlot, 2004: 236).

f) La granada es un círculo compuesto por infinitos círculos (sus granos), lo que conllevaría también la simbología del círculo: perfección y eternidad ${ }^{3}$.

De momento, dejaré todas las posibilidades abiertas, que se limitarán en las relaciones transmediales con el poema en prosa y la cita. Conviene también observar también que las $O$, en tanto que representantes visuales de los granos esparcidos de la granada, tendrían de igual modo las connotaciones simbólicas de esta.

Antes de pasar el análisis del poema en prosa, es interesante considerar brevemente la cita de Cioran que se incluye como parte de la composición. Ésta aporta claves temáticas (muerte, orden e infinito) que ya se habían previsto en la simbología de la granada. Además, aporta relaciones entre estos tres conceptos temáticos, ya que la muerte se asocia con el orden, contrapuesto a lo infinito.

Pasando a la interpretación del poema en prosa, se pueden observar tres campos asociativos, principalmente. En primer lugar, un campo asociativo relacionado con la vida, que incluiría la "sangre", el "don", "lo que nacía", "vivificar". En segundo lugar, un campo asociativo relacionado con la muerte: "palidez", "límite", "muerte". Por último, se encontraría el campo de lo cósmico en la "tierra", los "signos que rigen los astros", el "aire", la "memoria del árbol" y el "magma". Por lo tanto, encontraríamos que existe una contraposición entre los dos primeros campos (vida y muerte se oponen y se suceden) ante la pasividad del tercero. Además, otro elemento importante es la aparición de la primera persona al inicio ("mi sangre"), que contrasta con el resto del poema, enunciado en una tercera persona que incluso va a absorber, tras esta aparición inicial, a la primera: "lo que nacía del yo".

Las relaciones transpictóricas entre estos tres elementos previamente analizados dan lugar a varias macroestructuras posibles, de las cuales desarrollaré las dos más plausibles, según este estudio, a continuación. Derivado del análisis previo, podría decir que la macroestructura más probable y plausible consideraría la composición total como una unión de dos contrarios, representados en dos de las simbologías de la granada: la fecundidad (generativa y con un componente místico) frente al infinito, la creación continua y cíclica (vida y muerte) frente a lo siempre existente y, por lo tanto, no creado (naturalmente, desde una concepción no cristiana). De esta manera, el poema en prosa revelaría esta contradicción inherente del universo, justo en el momento de cierre de un ciclo: la sangre derramada da paso a la muerte, creación y destrucción cíclicas ante un cosmos pasivo e inmutable. Este ciclo de vida y muerte introduciría así "un orden en lo infinito" (siguiendo la cita de Cioran), dado que sería este ciclo el que mediría el tiempo, introduciendo en el cosmos un orden cíclico: el "ajuste entre lo múltiple y diverso en el seno de la unidad" que simboliza la granada para Cirlot.

\footnotetext{
${ }^{3}$ Esta característica deriva desde una interpretación teológica en la acepción de la fecundidad divina, como explica Chevalier (1991: 538).
} 
Además, esta concepción encajaría también con la simbología de la granada asociada a Perséfone, dado que la diosa griega, debido precisamente a este cíclico paso por el infierno y salida del mismo (salida de la tierra) de vuelta a la vida, se relaciona con la fecundidad agrícola, con el crecimiento estacional de los cultivos. Por lo tanto, la imagen gráfica de la granada dejando caer sus granos al espacio abierto e infinito de la página en blanco podría ser interpretada al revés: los granos (los instantes de creación en el cosmos, los ciclos temporales de vida y muerte) podrían no estar cayendo, sino elevándose en ese anhelo vertical hasta volver a su origen en el seno de la granada, en un ajuste o retorno "de lo múltiple y diverso" (los granos, la vida) "en el seno de la unidad" (la granada completa, el cosmos). Este sería el anhelo vertical: el anhelo de vivir y morir para completar el ciclo que introduzca orden y sentido (temporal, parcial y contingente) en el cosmos.

Una segunda macroestructura, si bien menos posible, podría basarse en las mismas consideraciones, pero focalizando la atención en que el hecho de que los granos de la granada son, de hecho, grafemas, letras $O$, hecho significativo que lo convierte en poema visual. De esta forma, la fecundidad anterior que se relacionaba con la vida y la muerte, al estar encarnada en letras, podría referirse a una fecundidad creativa literaria, que daría lugar a una interpretación metapoética, donde el anhelo vertical podría relacionarse con esa búsqueda poética de la perfección y la totalidad, a la manera de Claudio Rodríguez ("Siempre la claridad viene del cielo").

\section{CONCLUSIONES}

En primer lugar, a través de la revisión de las teorías semióticas acerca de la poesía visual, se han conseguidos dos fines. Por un lado, un fin teórico: describir la estructura y las relaciones semióticas de la poesía visual, así como explicar su funcionamiento y su recepción. Por otro lado, un fin práctico: se ha conseguido definir un método semiótico de análisis que nos ha dotado de las herramientas necesarias para la posterior interpretación de las obras estudiadas.

En segundo lugar, se ha complementado esta perspectiva semiótica con la revisión de las reveladoras consideraciones desde la teoría cognitiva, de la mano de Reuven Tsur y Mike Borkent. A través de la síntesis de ambas perspectivas, se ha logrado una mayor profundización teórica en la caracterización estructural, el funcionamiento y la recepción de la poesía visual. Desde un punto de vista práctico, se ha acoplado el método de análisis cognitivo de Borkent, basado en la relación entre percepción y cognición con la experiencia sensorial, al ya descrito método semiótico; logrando de esta manera un método semiótico-cognitivo que ha permitido profundizar más y entender nuevos aspectos del corpus propuesto. Además, se ha tomado de Tsur un criterio de valoración: la difícil integración entre nivel textual y visual, con un balance entre dificultad y simplicidad, que permite la percepción unitaria del poema visual. 
En tercer lugar, se ha realizado exitosamente un estudio práctico de un variado corpus, consiguiendo, por lo tanto, la interpretación de todas las obras mediante un método de análisis semiótico-estructural común para todas ellas, a pesar de las notables diferencias que éstas presentaban. En las producciones de Boso y Millán, como ya se preveía teóricamente, ha jugado un papel de máxima importancia la atención puesta sobre la materialidad de la palabra, del significante lingüístico, hasta llegar a perder su característica lingüística para convertirse en un significante plástico. En la obra de Janés, en cambio, el punto clave del estudio ha sido la integración de las relaciones transmediales, fundamentalmente basadas en el símbolo, establecidas entre los diferentes elementos de la composición, que han permitido elaborar una macroestructura capaz de dar una interpretación completa que integrara los elementos textuales y plásticos.

\section{REFERENCIAS BIBLIOGRÁFICAS}

BoHn, W. (1986). The Aesthetics of Visual Poetry. Cambridge: Cambridge University Press.

Borkent, M. (2014). "Visual Improvisation: Cognition, Materiality, and Postlinguistic Visual Poetry". Visible Language 48.3, 5-27.

(2015). Cognitive Ecology \& Visual Poetry: Toward a Multimodal Cognitive Poetics (PhD. Dissertation). Vancouver: The University of New Columbia.

Boso, F. (2006). La palabra islas. León: Universidad de León.

Chevalier, J. (DIR.) (1991). Diccionario de los símbolos. Barcelona: Herder.

Cirlot, J. E. (2004). Diccionario de símbolos. Madrid: Siruela.

DE Toro, A. (2007). "Dispositivos transmediales, representación y anti-representación.

Frida Kahlo: Transpictorialidad - Transmedialidad”. Comunicación 5, 23-65.

ElleströM, L. (2016). "Visual Iconicity in Poetry: Replacing the Notion of "Visual Poetry". Orbis Litterarum 71.6, 437-472.

GibBS, R. W. (2006). Embodiment and Cognitive Science. New York: Cambridge University Press.

JANÉS, C. (2006). Espacios translúcidos. Ávila: Ayuntamiento de Ávila.

LAFUENTE, J. M. Y MADERUELO, J. (2014). Escritura experimental en España, 1963-1983. Heras (Cantabria): La Bahía D.L.

Louvel, L. (2016). Poetics of the Iconotext. New York: Routledge.

MiLlÁn, F. (2005). La escritura en libertad: antología de poesía experimental. Madrid: Visor Libros.

Muriel Durán, F. (2000). La poesía visual en España (Siglos X-XX) (Antología). Salamanca: Ediciones ALMAR.

Pimentel, L. A. (2003). “Écfrasis y lecturas iconotextuales”. Poligrafias IV, 205-215. 
Romera CAStillo, J. (1980). "Poesía figurativa medieval: Vigilán monje hispanolatino del siglo X, precursor de la poesía concreto-visual”. 1616. Revista de la Sociedad Española de Literatura General y Comparada IV, 138-156.

SARABIA, R. (2007). La poética visual de Vicente Huidobro. Madrid: Iberoamericana.

Tsur, R. (1992). Toward a Theory of Cognitive Poetics. Amterdam: North-Holland Elsevier Science Publishing.

(2000). "Picture Poetry, Mannerism, and Sign Relationships". Poetics Today 21.4 (Winter), 751-781.

(2010). "Poetic Conventions as Cognitive Fossils". Style 44.4, 496-522.

VelÁzQueZ, J. I., ED. (1987). Guillaume Apollinaire: Caligramas. Madrid: Cátedra. 


\section{ANEXO}

\section{Figuras 1 y 2: subconjuntos 1 y 2 de La palabra islas (Boso, 2006: s. p.)}

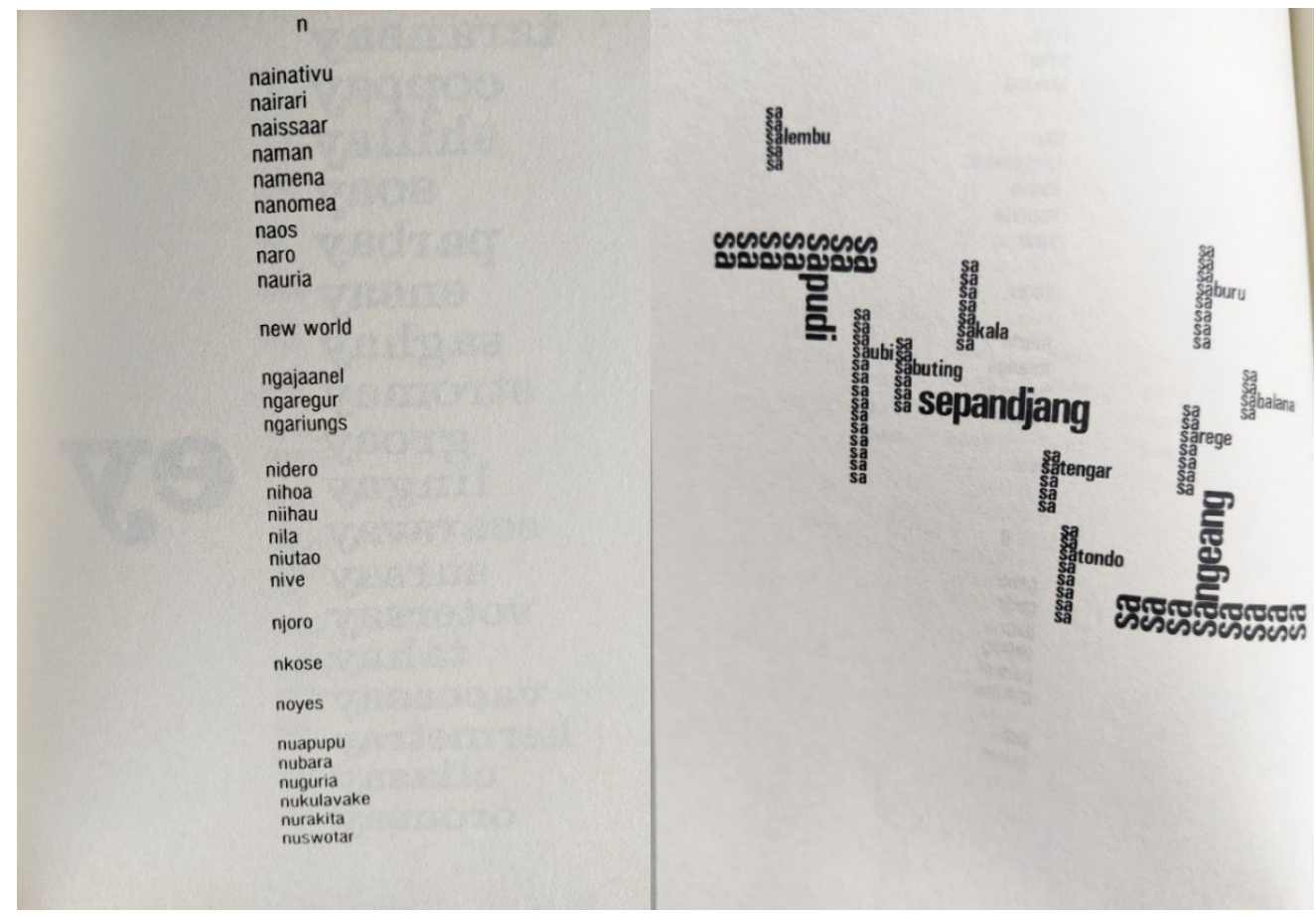

Copyright de Felipe Boso y la Universidad de León. Reproducido con el permiso de Publicaciones Universidad de León.

2. Figura 3: subconjunto 3 de La palabra islas (Boso, 2006: s. p.)

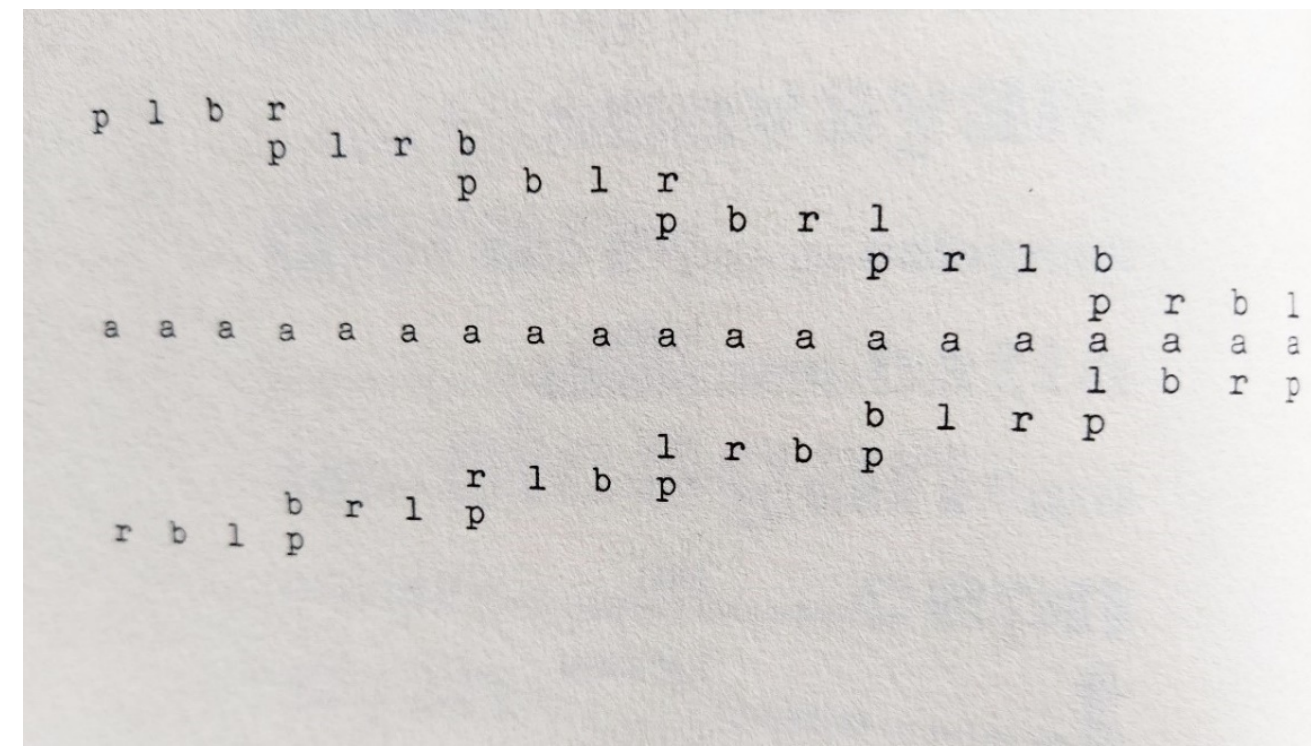

Copyright de Felipe Boso y la Universidad de León. Reproducido con el permiso de Publicaciones Universidad de León. 


\section{Figura 4: De La palabra islas (Boso, 2006: s. p.)}

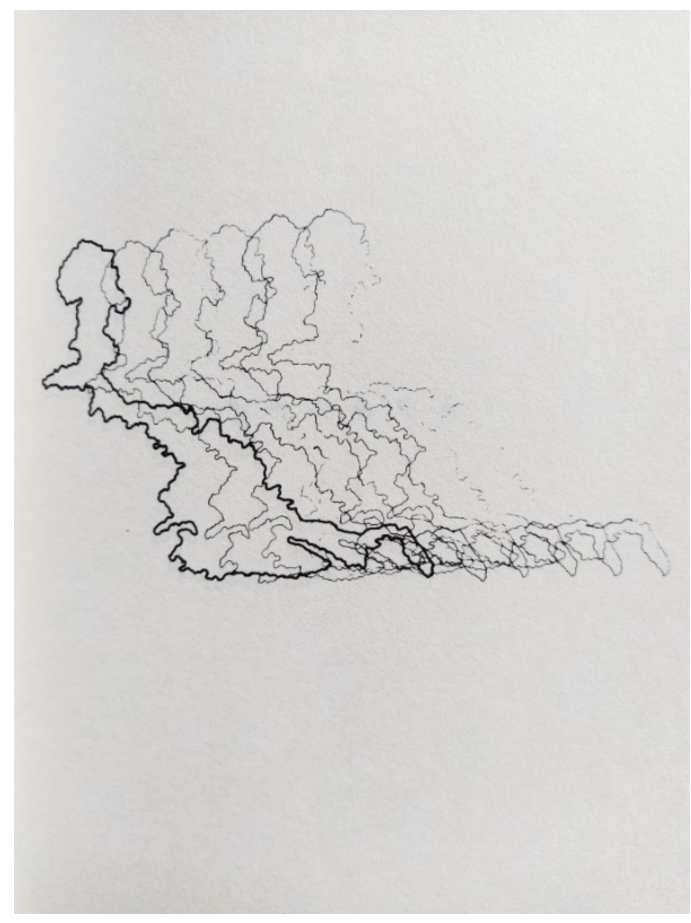

Copyright de Felipe Boso y la Universidad de León. Reproducido con el permiso de Publicaciones Universidad de León.

4. Figura 5 y 6: De La palabra islas (Boso, 2006: s. p.)

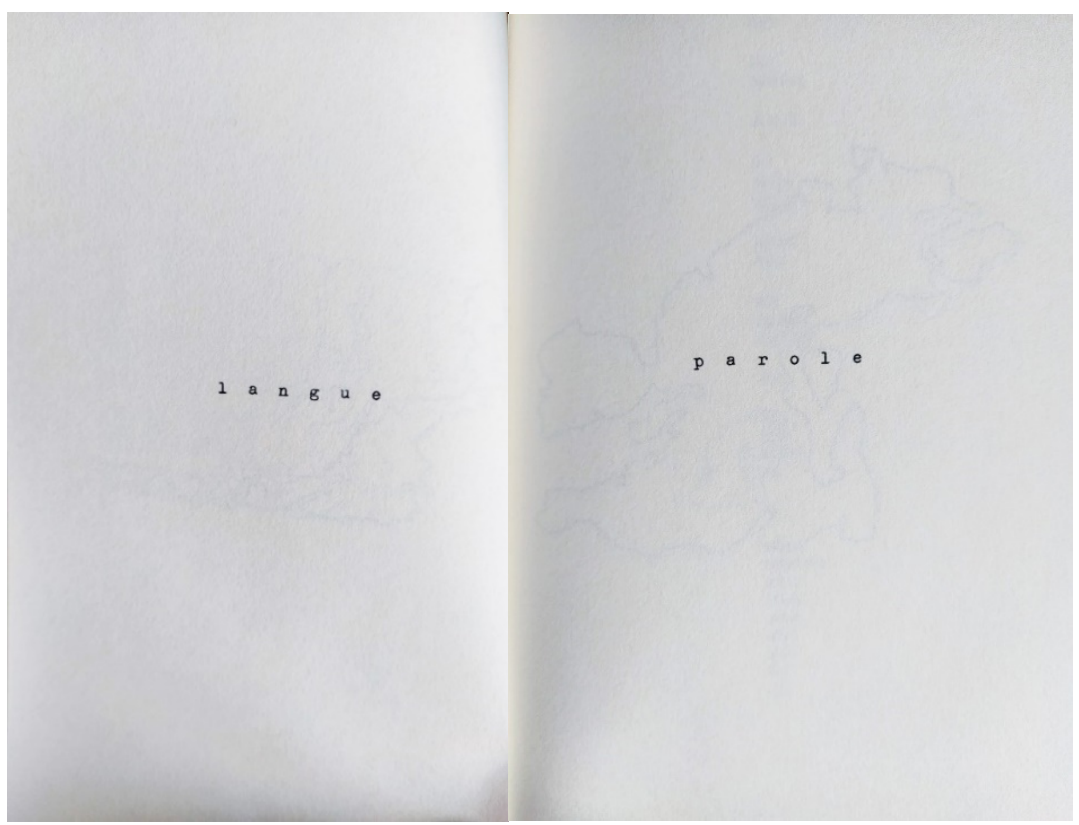

Copyright de Felipe Boso y la Universidad de León. Reproducido con el permiso de Publicaciones Universidad de León. 


\section{Figura 7: De La palabra islas (Boso, 2006: s. p.)}

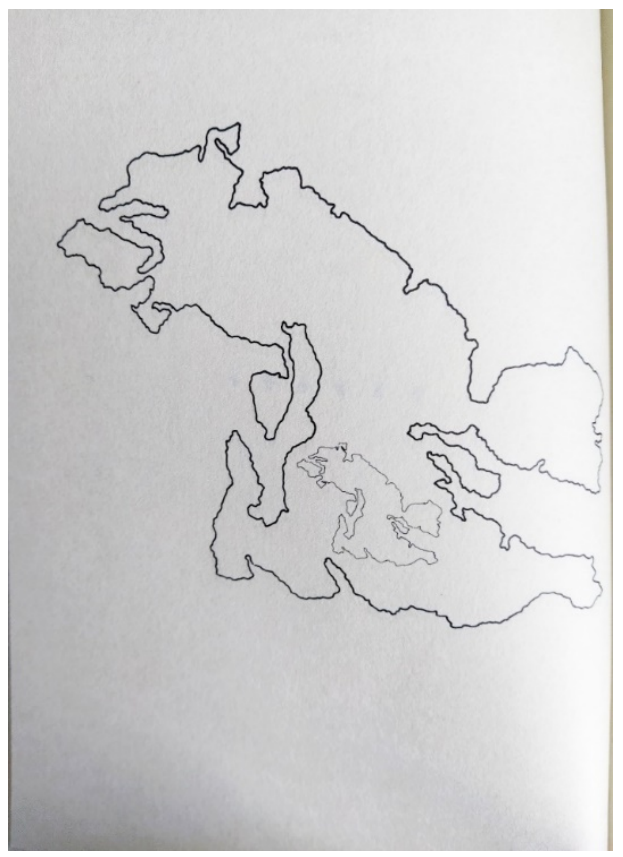

Copyright de Felipe Boso y la Universidad de León. Reproducido con el permiso de Publicaciones Universidad de León.

\section{Figura 8: Criptograma Sueño (Millán, 2005: s. p.)}

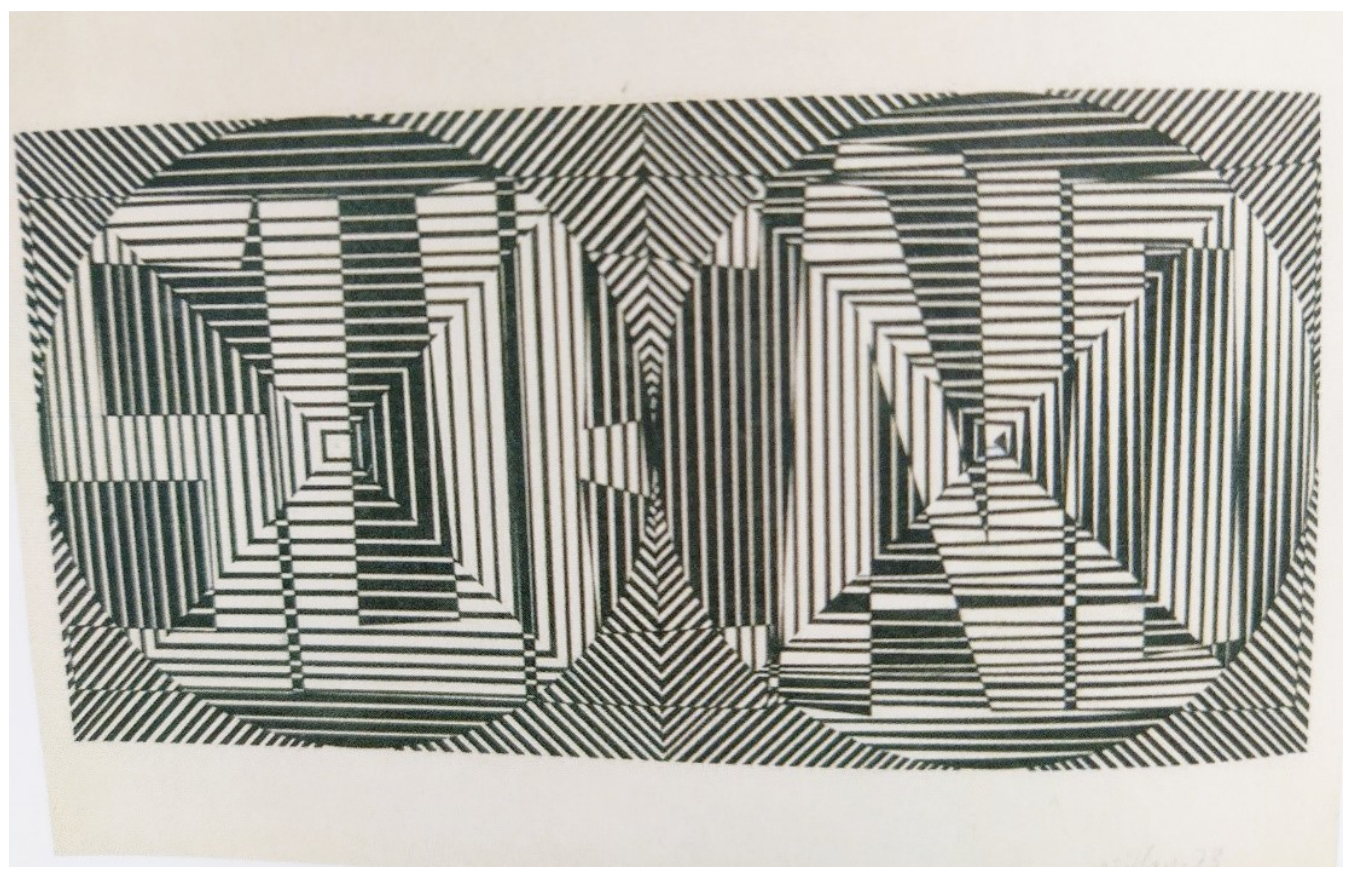

Copyright de Fernando Millán y la editorial Visor Libros. Reproducido con el permiso de la mencionada editorial. 


\section{Figura 9: Criptograma Mentira (Millán, 2005: s. p.)}

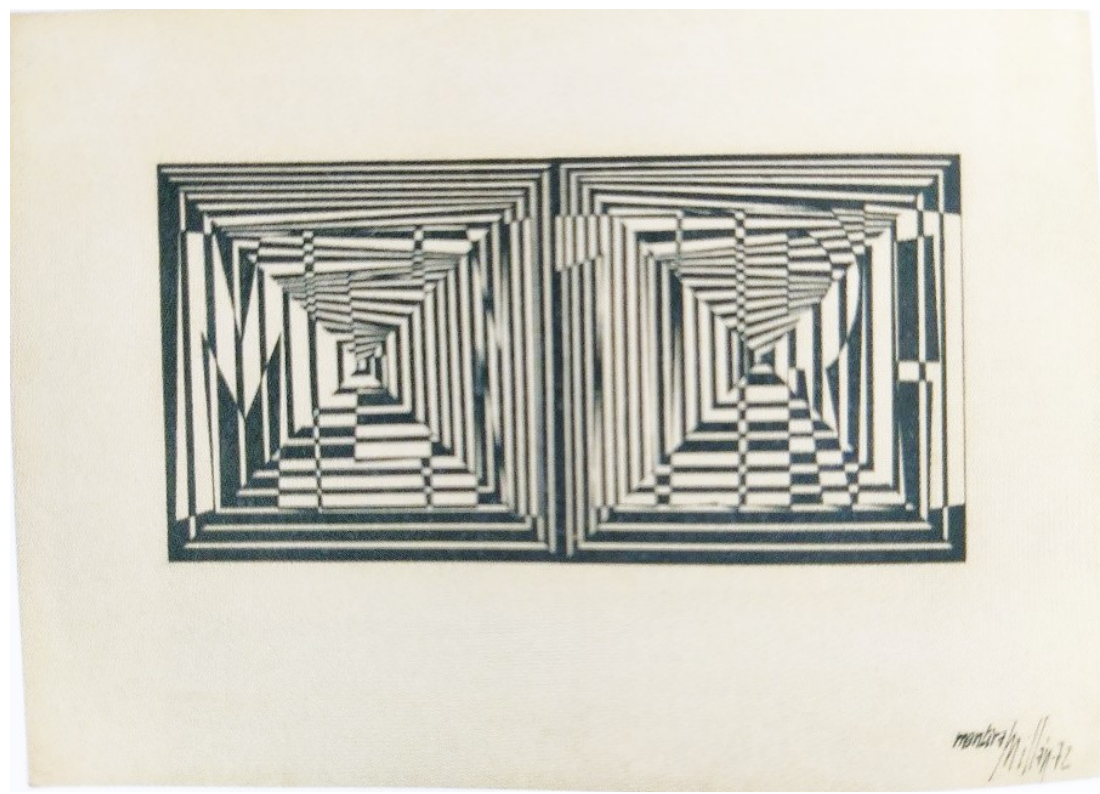

Copyright de Fernando Millán y la editorial Visor Libros. Reproducido con el permiso de la editorial Visor Libros.

8. Figura 10: De Ariadna y el sueño (Millán, 2005: s. p.)

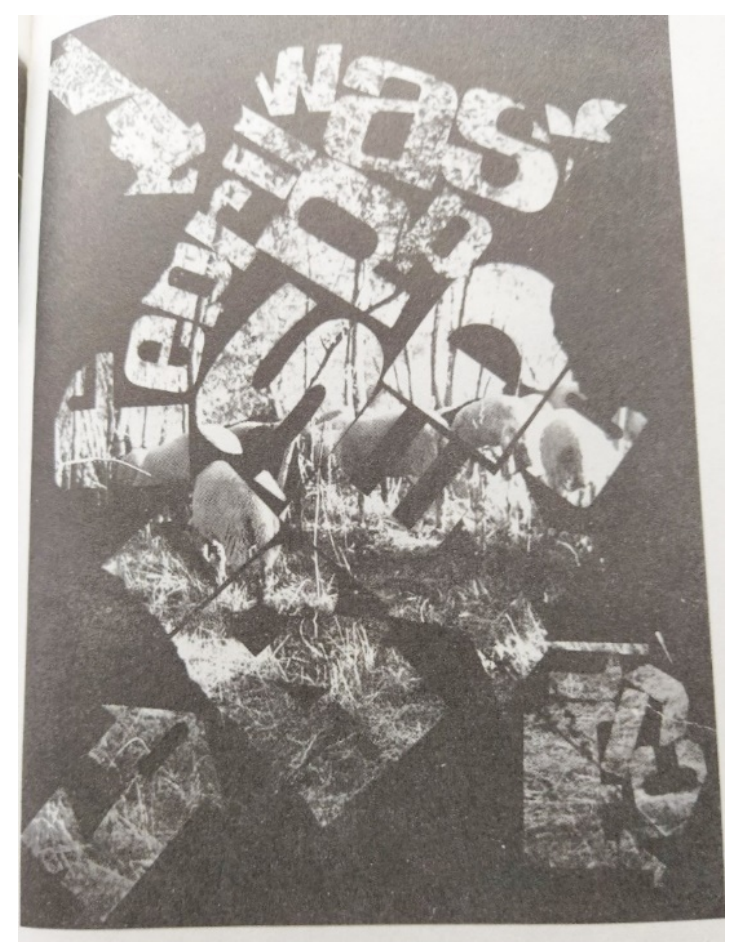

Copyright de Fernando Millán y la editorial Visor Libros. Reproducido con el permiso de la editorial Visor Libros. 


\section{Figura 11: “Anhelo vertical”, Espacios translúcidos, Clara Janés (2006: 28-29)}

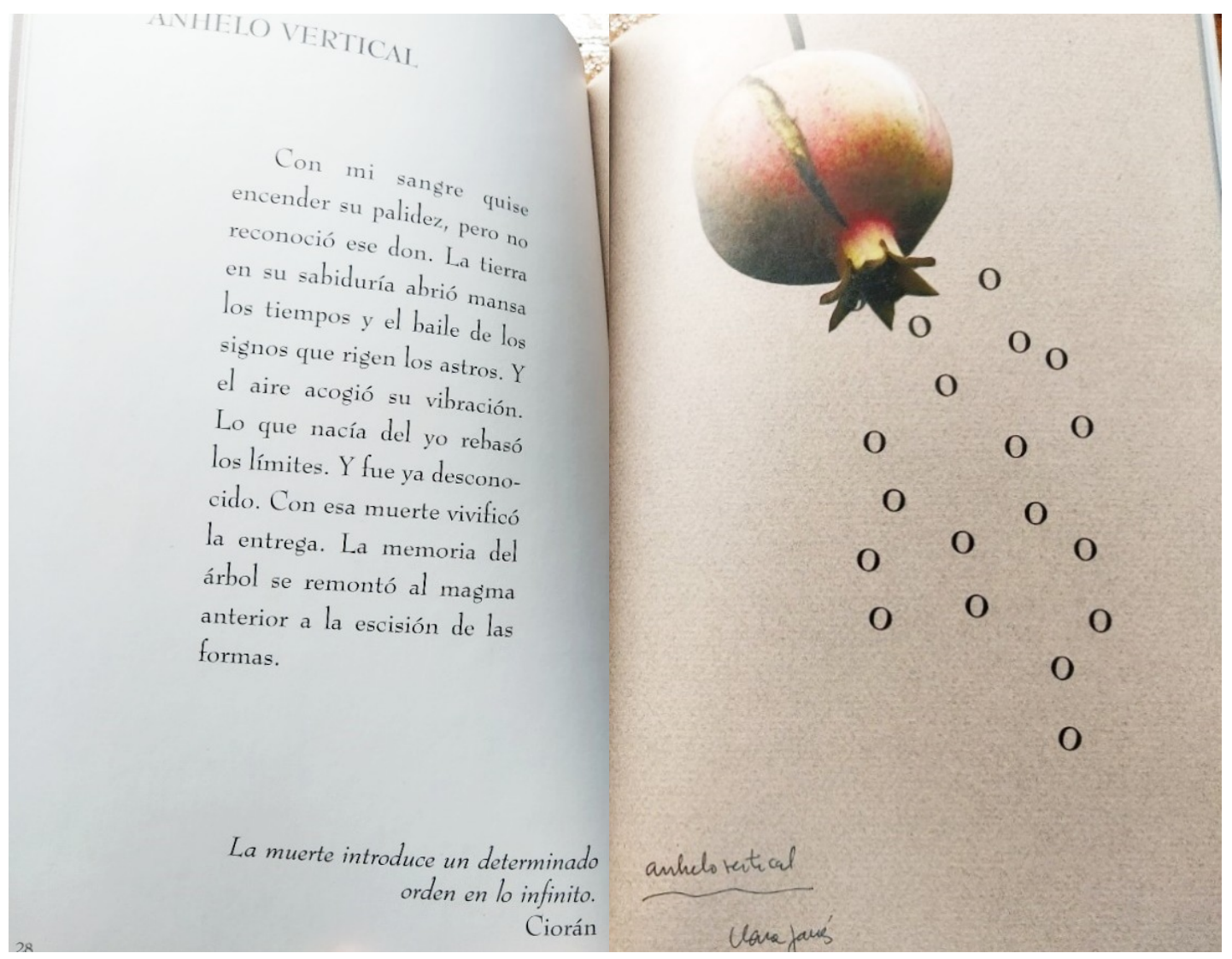

Copyright de Clara Janés y el Ayuntamiento de Ávila. Reproducido con el permiso del Ayuntamiento de Ávila.

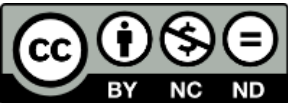

This work is licensed under a Creative Commons AttributionNonCommercial-NoDerivatives 4.0 International (CC BY-NC-ND).

El/la firmante del artículo se responsabiliza de las licencias de uso de las imágenes incluidas.

Fecha de recepción: 17/01/2021

Fecha de aceptación: 04/05/2021 